\title{
COVID-19 Pandemic Lockdown Resulting in an Unusual Rectal Foreign Body in a Young Male
}

\author{
Allauddin ${ }^{1 *}$, Gulalai Rehman ${ }^{2}$, Abdul Kareem Zarkoon $^{3}$, Bibi Nasira $^{4}$, and Immad Uddin Khan ${ }^{5}$ \\ ${ }^{1}$ Bolan Medical Complex Hospital, Quetta, Pakistan; ${ }^{2}$ Balochistan Institute of Nephro-Urology, Quetta, Pakistan; ${ }^{3}$ Balo- \\ chistan Institute of Nephro-Urology, Quetta, Pakistan; ${ }^{4}$ Balochistan Institute of Nephro-urology Quetta, Pakistan; and \\ ${ }^{5}$ Student of $8^{\text {th }}$ Class City School, Quetta, Pakistan. \\ *Correspondence: drallauddin5@gmail.com (Dr. Allauddin, Senior Registrar General Surgery, Bolan Medical Complex \\ Hospital, Quetta, Pakistan).
}

\begin{abstract}
Foreign body rectum may cause serious consequences, especially in psychologically vulnerable patients, In critical conditions like pandemic COVID-19, when depression, fear boredom, loneliness such incidence may occur. An 18 years old young male presented in emergency with a foreign body rectum. He was a laborer on daily wages. During the COVID-19 pandemic, loneliness, anxiety, and unemployment have exposed him to bizarre behavior, resulting in inserting potato into his rectum. He denied any history of homosexuality. The diagnosis was made by examination. Per rectal examination found FB just above the anal verge. The foreign body was removed rectally under G/A. He was then referred to a psychiatrist for evaluation.
\end{abstract}

Keywords: Foreign body, Potatoes, Stress, Rectal, Foreign body, Lockdown, COVID-19, and Quarantine.

\section{INTRODUCTION:}

The hospital presentation of retained foreign body rectum is not rare. although data are still deficient ("ayantunde AA. approach to the diagnosis and management... - Google Scholar,") about the actual incidence (Goldberg and Steele, 2010). The first report of rectal foreign body dated back to $16^{\text {th }}$ century (Vinkers et al., 2020).The incidence of rectal foreign bodies shall continue to rise due to use of different objects for sexual purpose. With the outbreak of 2019 coronavirus disease (Covid-19), with Stay-at-home orders forced all of us to experience a critical time (Islam et al., 2021).

The adverse psychological effects related to the lockdown might reveal a susceptibility to unnatural behavior in subjects. Depression, anxiety, frustration, boredom (Ozbilgin et al., 2015) fear of infection, stress of unemployment (Brooks et al., 2020) felt loneliness, nervousness (Taylor et al., 2020), irritability especially in psychologically vulnerable subjects (Wang et al., 2020). This probably happened to our 18-year-old male patient was affected by loneliness (Huang et al., 2020) unemployment because he was a blue-collar laborer on daily wages. These patients arise to emergency department with lower abdominal, anorectal pain or rectal bleeding. Usually such patient presentlate to hospital, after initial several failed attempts to remove by himself ("ayantunde AA. approach to the diagnosis and management... - Google Scholar,"). In order to avoid social embarrassment and apparent shame, in fact such patient presents both diagnostic and treatment challenges to ER personals (Goldberg and Steele, 2010). Management of such patients needs methodical approach. The ultimate result of every case should be successful and safe removal of foreign body, 
in such a way to respect the patient's right to privacy, dignity and confidentiality (Goldberg and Steele, 2010).

\section{Patient information}

A young 18 years old male unmarried, Presented with history of foreign body in rectum since last 3 days. He was working on daily wages in a private construction company. According to the patient during the period of lockdown in pandemic of Covid-19 in June- July, he become jobless and confined to his residence, he was living with two other persons when one day, he just make a bet with his Colleague that he can sit on the potato without any danger but suddenly he realized that the potato was inside in the rectum with pain. $\mathrm{He}$ tried to evacuate manually by himself but not successful. Anxious looking young male with no prior history of psychiatric illness or medication, he denied of any previous such history, homosexuality or sexual per-version. On general physical examination, the patient was very anxious in agony, pain and was constipated. His BP was 140/85mmHGPulse 105, he was a febrile with a respiratory rate of 18.Abdominal examination mild fullness, non-tender. On digital examination of rectum the anus was patulous with cracks in skin and internally small tears and edematous mucosa. Digital examination was mildly painful; a firm to hard object was felt within $4 \mathrm{~cm}$ of anal verge. Manual evacuation with fingers tried which was not successful. The patient was admitted in the ward and bas line investigations were done, complete blood picture (CBC) showed hemoglobin of $13.5 \mathrm{~g}$ per $\mathrm{dl}$. Screening test for hepatitis B, hepatitis C, HIV, were non-reactive, blood sugar was $90 \mathrm{mg} / \mathrm{dl}$ and urea creatinine were in normal range Abdominal x-ray was unremarkable. He was shifted to operation theatre after anesthesia induction lithotomy position was made, examination was done in general anesthesia, and a huge foreign body was felt by a digital rectal examination. Proctoscopy examination confirmed in the rectuma yellowish firm to hard foreign. It was removed by gentle manipulation with finger and instruments per rectally, gently dilating the anal sphinter, initially some pieces removed, latter on entire body was retrieved. Surprisingly it was a large potato, approximately it was $14 \times 6 \mathrm{~cm}$. post-operative recovery was smooth he was discharged next day.
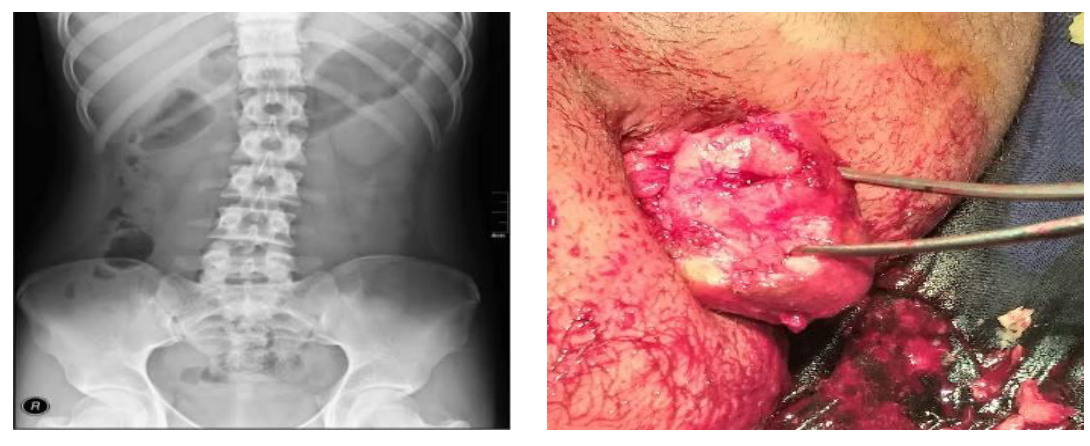

Fig 1: X-ray abdomen.

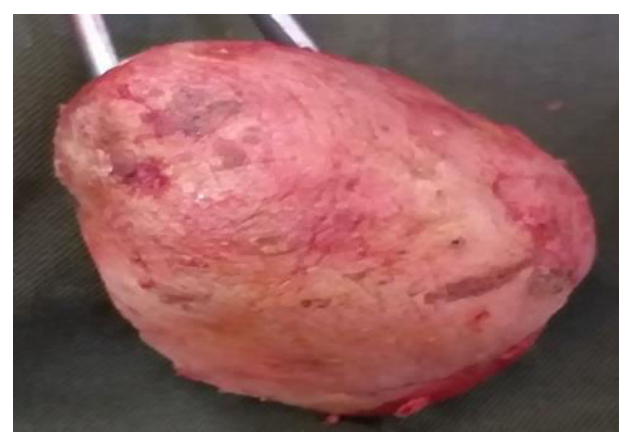

\section{DISCUSSION:}

In adults insertion and retention of objects in rectum are common, such objects are in majority for sexual perversion or criminal intent (Child, 2020), Occasionally may be due to self-treatment of anorectal diseases. The objects may range from sex toys, fruits, vegetables, bottles, batteries etc. In psychologically vulnerable persons with circumstances like pandemic, COVID-19, where strict domestic quarantine adopted to control transmission may behaved strangely, because during Covid-19 lockdown strategies, depresssion, boredom, nervousness and feeling of loneliness, and unemployment (Vishal et al., 2018) was very common, in such conditions persons may perform unnatural and uncommon task, especially psychological vulnerable persons (Eftaiha et al., 1977).

Such patient may have tried previously such sexual perversion. The patient sought medical treatment when the inserted foreign body could not be removed by them, or if it causes pain, bleeding or some other complications. In Quarantine boredom, loneliness and unemployment, with anxiety and depression may reveala susceptibility to unhealthy demeanors (Vinkers et $a l ., 2020)$ including sexual perversion. This finding is 
also endorsing, the warning about the outcomes of children's home confinement, not only influencing their mental wellbeing but also their overall physics (Eftaiha et al., 1977). The stress level and anxiety as a result of COVID-19 are similar, which were reported during past pandemics (SARS AND 2009 H1N1 pandemic) anxiety is an important driver of behavior (Brooks et al., 2020). In our case young 18 year male, although denying any history of sexual perversion. The consequence of COVID-19 lockdown, unemployment, boredom, may force him to bizarre behavior for possible sexual amusement. Most of the patients Conceal the history of insertion of foreign body, will present with lower-abdominal pain, anal pain and bleeding (Child, 2020). As a clinician hi-index of suspicion should arise, when come across with doubtful history and clinical findings. A thorough abdominal and per rectal examination should be done to rule out peritonitis, any anal tear and to confirm sphincter integrity. X-ray abdomen and pelvis should be the initial investigation to rule out foreign body, number, shape, size, color and site. If foreign body is not visible on X-ray, CT-scan must be done, but both X-ray and CT-scan are not necessary, if clinically patient is stable and perectal examination confirms foreign body in rectum. Patient X-ray should be marked with correct name and age, because due to social embarrassment and disgrace, the patient may try to change the X-ray film with other patients (Lake et al., 2004). In our case the $\mathrm{X}$-ray pelvises was unremarkable and per rectal examination confirm the foreign body in the rectum just above the anal verge, so no CT-scan was performed.

Eftaiha et al. ( 1977) classified the foreign bodies lying above the recto sigmoid junction are considered high lying, difficult to remove per rectum, need laparotomy. Gentle attempt to retrieve per rectally should be tried even with the help of proctoscope and sigmoidoscope, repeated attempt and unusual force should be avoided it may damage sphincter. The surgical intervention predictors are foreign body larger than 10 $\mathrm{cm}$ hard and with sharp edges, located in the proximal rectum and above (Cohen and Sackier, 1996). In our case it was immediately above the anal verge which was removed per rectally with gentle force using kelloid forcep and finger manipulation under general anesthesia.

UniversePG I www.universepg.com

\section{CONCLUSION:}

Keeping in view the weird situation like lockdown during pandemic Covid-19 when there was anxiety, fear, loneliness, unemployment, a careful history and thorough physical examination and critical thinking is very mandatory to rule out such unusual cases. High index of suspicion with prompt work up including $\mathrm{X}$ ray, history and clinical examination will direct one towards diagnosis. The management is individualized depending on size, shape; absence of peritonitis and rectal injury. Treatment options includes manual extraction sigmoidoscopy or laparotomy. After treatment, proper psychiatric evaluation should be done.

\section{ACKNOWLEDGEMENT:}

We acknowledge the cooperation of Immad Uddin Khan for his technical support.

\section{CONFLICTS OF INTEREST:}

Authors have declared that no competing interests exist.

\section{REFERENCES:}

1) Ayantunde AA. approach to the diagnosis and management... - Google Scholar [WWW Document], URL-

https://scholar.google.com/scholar?hl=en\&as_s $\mathrm{dt}=0 \% 2 \mathrm{C} 5 \& \mathrm{q}=$ ayantunde $+\mathrm{AA} .+$ approach $+\mathrm{to}+\mathrm{t}$ he+diagnosis+and+management+retained+recta $1+$ bodies\&btnG $=$

2) Brooks et al. (2020). The psychological impact of quarantine and how to reduce it: rapid review of the evidence. The lancet, 395, 912-920. https://doi.org/10.1016/S0140-6736(20)30460-8

3) Child, T.L., (2020). Pandemic school closures: risks and opportunities. Lancet Child Adolesc. Health, 4(341).

https://doi.org/10.1016/S2352-4642(20)30105-X

4) Cohen, J.S., Sackier, J.M., (1996). Management of colorectal foreign bodies. J. R. Coll. Surg. Edinb, 41, 312-315. https://doi.org/10.1111/j.1463-1318.2004.0069 9.x.

5) Eftaiha, M., Hambrick, E., Abcarian, H., (1977). Principles of management of colorectal foreign bodies. Arch. Surg, 112, 691-695. https://link.springer.com/chapter/10.1007/978-3$\underline{662-10169-8 \quad 39}$ 
6) Goldberg, J.E., Steele, S.R., (2010). Rectal foreign bodies. Surg. Clin. 90, 173-184.

7) Huang et al. (2020). Clinical features of patients infected with 2019 novel coronavirus in Wuhan, China. The lancet, 395, 497-506.

https://link.springer.com/chapter/10.1016/S01406736(20)30183-5.

8) Islam MS, Dayem SB, and Amin M. (2021). Impact of host genetic players on Covid-19 disease severity: a review of current knowledge and future prospect, Bangladesh. Eur. J. Med. Health Sci., 3(4), 79-87. https://doi.org/10.34104/ejmhs.021.079087

9) Lake et al. (2004). Management of retained colorectal foreign bodies: predictors of operative intervention. Dis. Colon Rectum, 47, 1694 1698.

https://link.springer.com/chapter/10.1007/s10350004-0676-4.

10) Ozbilgin, M., Arslan, B., Yakut, M.C., Aksoy, S.O., Terzi, M.C., (2015). Five years with a rec- tal foreign body: A case report. Int. J. Surg. Case Rep, 6, 210-213.

11) Taylor et al. (2020). Development and initial validation of the COVID Stress Scales. J. Anxiety Disord. 72, 102232.

https://doi.org/10.1016/j.janxdis.2020.102232. Epub 2020 May 4.

12) Vinkers et al. (2020). Stress resilience during the coronavirus pandemic. Eur. Neuro-psychopharmacol. 35, 12-16.

13) Vishal, V., Meena, N., Mahendra, M., (2018). A rare case of presence of unusual foreign body in rectum in homosexual male. Indian J. Case Rep. 236-238. https://doi.org/10.32677/IJCR.2018.V04.I03.022

14) Wang, C., Horby, P.W., Hayden, F.G., Gao, G.F., (2020). A novel coronavirus outbreak of glo-bal health concern. The lancet, 395, 470473.

https://doi.org/10.1016/S0140-6736(20)30185-9.

Citation: Allauddin, Rehman G, Zarkoon AK, Nasira B, and Khan IU. (2021). COVID-19 pandemic lockdown resulting in an unusual rectal foreign body in a young male. Eur. J. Med. Health Sci., 3(6), 132-135. https://doi.org/10.34104/ejmhs.021.01320135 @) ( 